\title{
Feasibility of Postoperative Radiotherapy Using Conventional Fractionation for Lymph Node Metastasis from Cutaneous Melanoma
}

\author{
YEON JOO KIM ${ }^{1}$, SI YEOL SONG ${ }^{1}$, WANLIM KIM ${ }^{2}$, SEONG-YUN JEONG ${ }^{3}$, WONSIK CHOI ${ }^{4}$, \\ HYOUNG UK JE ${ }^{5}$, JONG-SEOK LEE ${ }^{2}$ and EUN KYUNG CHOI ${ }^{1}$ \\ Departments of ${ }^{1}$ Radiation Oncology, ${ }^{2}$ Orthopedic Surgery, and ${ }^{3}$ Asan Institute for Life Science, \\ Asan Medical Center, University of Ulsan College of Medicine, Seoul, Republic of Korea; \\ ${ }^{4}$ Department of Radiation Oncology, Gangneung Asan Hospital, \\ University of Ulsan College of Medicine, Gangneung, Republic of Korea; \\ ${ }^{5}$ Department of Radiation Oncology, Ulsan University Hospital, \\ University of Ulsan College of Medicine, Ulsan, Republic of Korea
}

\begin{abstract}
Aim: In the present study we assessed if postoperative radiotherapy (PORT) using conventional fractionation confers a benefit in cutaneous melanoma patients with lymph node (LN) metastasis. Patients and Methods: Sixty-two patients with axillary or inguinal $L N$ metastasis were retrospectively reviewed. Twenty-eight patients received PORT. The median RT dose was 50 Gy in 25 fractions. The high-risk group was defined by the presence of any of the following: $\geq 3 \mathrm{LNs}$, size $\geq 3 \mathrm{~cm}$, extranodal extension. Results: The median follow-up time was 34 months. PORT showed a significant benefit on 5-year axilla-inguinal recurrence-free survival (RFS) in high-risk patients (RT 100\% vs. No-RT 37\%, $p=0.001$ ). There was also a benefit of $R T$ on 5-year out-field RFS in the high-risk population ( $R T$ 93\% vs. No-RT 29\%, $p=0.002$ ). There were no $\geq$ grade 2 lymphedemas after RT. Conclusion: PORT using conventional fractionation for high-risk $L N$ metastasis from cutaneous melanoma is feasible with comparable regional control and minimal toxicity.
\end{abstract}

Postoperative radiotherapy (PORT) improves local control of metastatic lymph nodes (LNs) with high-risk features from cutaneous melanoma (1-5). The definition of high-risk varies

Correspondence to: Si Yeol Song, MD, Ph.D., Associate Professor, Department of Radiation Oncology, Asan Medical Center, University of Ulsan College of Medicine, 88 Olympic-ro 43-gil, Songpa-gu, Seoul 05505, Republic of Korea. Tel: +82 230104431, Fax: +82 230106950, e-mail: siyeol.song@gmail.com

Key Words: Melanoma, lymphatic metastasis, postoperative radiotherapy. according to the center in question but can be summarized as the following: 2 or more LNs, large size, extranodal extension, and recurrent LN disease (1-3, 6-8). Although PORT has not been shown to improve overall survival, local failure at the LN itself can cause several morbidities, such as pain, ulceration, lymphedema, plexopathy, and paralysis. Thus, it seems reasonable for selected patients with high risk of regional recurrence after LN dissection to receive PORT.

Previous studies have focused on Caucasians. Cutaneous melanoma is the most common skin cancer in Caucasians with incidence rates of 21.9 in the United States and 55.9 in Australian males per 100,000 patient-years (9). However, the incidence of melanoma in Asia is only 0.2-0.5 per 100,000 patient-years (10). Accordingly, there are no data on PORT to the nodal area in cutaneous melanoma in Asian patients. Some studies described differences in clinicopathological features according to ethnicity, particularly the type of melanoma $(11,12)$. The most common histological subtype in Asians is acral lentiginous melanoma (ALM), which accounts for $\sim 50 \%$ of all melanomas, whereas it constitutes only 2-3\% in Caucasians. In addition, genetic mutations in $B R A F$ genes, which have been related to clinicopathologic features and melanoma prognosis, also show differences in incidence according to ethnicity (Caucasian 66\% vs. Chinese $25.5 \%$, Japanese $26 \%$, Korean $11.9 \%$ ) (13-15). We assumed that ethnic difference might affect the clinical outcomes of PORT.

There is the issue of the PORT fractionation scheme. Hypofractionated RT (30 Gy in 5 fractions) has long been the mainstay of PORT for melanoma, although conventional fractionation on consecutive days is usually adopted for other diseases. Melanoma has generally been considered a highly radio-resistant tumor based on early in vitro studies of 
radiobiology suggested that melanoma cells possess a broad shoulder on the cell survival curve $(16,17)$. To overcome this radioresistance, a higher dose per fraction was initially introduced. Chronic lymphedema has been a worrisome complication of hypofractionated PORT with 5-year symptomatic lymphedema rate of $20 \%$ in axilla, and $27 \%$ in groin LN disease (6). We used a conventional fractionation regimen as our treatment strategy to reduce the risk of late radiation toxicities not only lymphedema, but dermatitis, neuropathy, and joint stiffness.

In the present study, we assessed if PORT using conventional fractionation conferred an added benefit in an Asian population and determined which patients benefitted most. In addition, we identified the prognostic factors for cutaneous melanoma patients with high-risk LN metastasis.

\section{Patients and Methods}

Patients. Patients diagnosed and treated for axillary and inguinal metastasis from cutaneous melanoma between March 1997 and June 2016 were identified through a search of our institutional database. Because there are reports that head and neck melanoma has a worse prognosis than that of other skin sites and different toxicity profile, we excluded cases of cervical metastasis from head and neck melanoma $(6,18)$. In total, 62 patients were enrolled. Their clinical data were obtained through retrospective review. A waiver of informed consent was obtained from the local institutional review board before analysis. Because there is no consensus in our center on the indication for PORT in cutaneous melanoma patients with regional $\mathrm{LN}$ metastasis, patients were classified into 2 groups: 1 ) RT group who received PORT $(n=28)$, and 2) No-RT group who were not treated with PORT with or without another adjuvant therapy such as interferon alpha or chemotherapy $(n=34)$. Patients' characteristics including sex, age, performance status, primary site, depth of invasion, pathological subtype, LN field, numbers of positive LNs, maximum size of LN, extranodal extension, type of surgery, year of diagnosis and use of systemic therapy were all identical between RT and No-RT groups. We defined the high-risk group as the presence of any of the following: $\geq 3 \mathrm{LNs}$, size $\geq 3 \mathrm{~cm}$, extranodal extension.

Surgery. All patients underwent wide local excision to remove the primary lesion with adequate margins. Distal phalangeal amputations were also performed if needed. Unless LN metastasis was suspicious in physical examination and/or imaging studies, surgical nodal staging was not routinely performed. In the present study, recurrent LN disease was defined as nodal failure occurred after 6 months from the surgery of the primary lesion. For clinically detected LN metastasis, $\mathrm{LN}$ dissection was performed in most cases and 2 patients in each group were treated with $\mathrm{LN}$ excision.

Postoperative radiotherapy. For PORT, 3-dimensional conformal RT (3D-CRT) was used. Patients with axillary metastases were treated in a supine position with their arms akimbo. Patients with inguinal metastases were treated in a supine position with their leg abducted and externally rotated. Planning computed tomography (CT) was obtained by a CT scanner with a slice thickness of $2.5 \mathrm{~mm}$. Six and $15 \mathrm{MV}$ photon beams were irradiated from a single direction to 3 directions, such as the anterior and oblique. The clinical target volume (CTV) covered the surgical scar and axillary levels I-III for axillary RT. The scar and inguinal nodal areas were contoured as the CTV for inguinal RT. Planning target volume (PTV) margins ranged from $0.7-1.0 \mathrm{~cm}$. In 7 patients, the radiation field was reduced for the final 6-10 Gy irradiation. The reduced CTV was confined to the tumor bed area and PTV margins were also expanded to between 0.7 and $1.0 \mathrm{~cm}$. The median RT dose was $50 \mathrm{~Gy}$ (range=46-60) with a median fraction size of 2 Gy (range $=1.8-2.2$ Gy) (Table I). The most common RT regimen was 50 Gy in 25 fractions (54\%), which was identical to a median biological equivalent dose (BED) of $90 \mathrm{~Gy} 2.5$ (range $=82.8-108$ ). The BED was calculated using an $\alpha / \beta$ ratio of 2.5 Gy for melanoma (19).

Chemotherapy. Some patients were also treated with adjuvant interferon alpha-2b $(n=13)$ or chemotherapy $(n=9)$. No patients received both interferon alpha- $2 b$ and chemotherapy. Chemotherapy consisted of 4 to 6 cycles of dacarbazine/carmustine/cisplatin/ tamoxifen or cisplatin/vinblastine/dacarbazine.

Statistical analysis. The primary endpoint was 5-year axilla-inguinal recurrence-free survival (RFS). Secondary endpoints were 5-year out-field recurrence-free survival (ofRFS), which included regional failure that occurred outside the axilla and inguinal area, distant metastasis-free survival (DMFS), and toxicities. Patients were followed up every 3 months for the first 2 years with ultrasonography (US) or CT of the primary site. Subsequently, follow-up was done every 6 months with US or CT until 5 years and annually thereafter. Acute and late toxicities were evaluated using the Common Terminology Criteria for Adverse Events (CTCAE) v.4.03. Acute toxicities were defined as adverse events within 3 months after the completion of RT. The Kaplan-Meier method was used to estimate survivals. Univariate analysis was performed according to the log rank test. All statistical tests were 2-sided, and a $p$-value of less than .05 was considered statistically significant. The IBM SPSS Statistics 21 package was used for all analyses.

\section{Results}

A total of 34 patients were classified into the high-risk group. Among them, 17 were treated with PORT. Characteristics of the patients in the high-risk group are listed in Table II. Extranodal extension was significantly different in RT and No-RT groups owing to the higher incidence of unknown extranodal extension status in No-RT group than RT group.

Axilla-inguinal recurrence and out-field regional recurrence. The median follow-up time was 34 months (range=3-181 months) from the LN dissection or excision date. With total 62 patients, 5-year axilla-inguinal RFS was $76 \%$. There was a significant difference in 5-year axilla-inguinal RFS (RT $92 \%$ vs. No-RT 63\%, $p=0.019$; Figure 1A). Survival analysis was stratified with our high-risk group criteria. There was no significant difference in the low-risk group (RT $81 \%$ vs. NoRT $88 \%, p=0.700$ ), whereas a significant difference was shown in the high-risk group (RT $100 \%$ vs. No-RT $37 \%$, $p=0.001)$. Five-year ofRFS of total patients was $63 \%$. There 
Table I. Radiotherapy characteristics.

\begin{tabular}{lc}
\hline & RT group $(\mathrm{n}=28)$ \\
\hline RT dose, Gy & \\
Median (range) & $50(46-60)$ \\
Fraction size, Gy & $2(1.8-2.2)$ \\
Median (range) & \\
BED*, Gy $_{2.5}$ & $90(82.8-108)$ \\
Median (range) & 19 \\
$\leq 90$ & 9 \\
$>90$ & 15 \\
RT regimen (BED*, Gy 2.5$)$ & 4 \\
50 Gy/25 fractions $(90)$ & 3 \\
$56 \mathrm{~Gy} / 28$ fractions $(100.8)$ & 2 \\
$50.4 \mathrm{~Gy} / 28$ fractions $(86.7)$ & 1 \\
$60 \mathrm{~Gy} / 30$ fractions $(108)$ & 1 \\
$46 \mathrm{~Gy} / 23$ fractions $(82.8)$ & 1 \\
$48.4 \mathrm{~Gy} / 22$ fractions $(91)$ & 1 \\
$54 \mathrm{~Gy} / 27$ fractions $(97.2)$ & \\
$52.8 \mathrm{~Gy} / 24$ fractions $(99.3)$ & \\
\hline
\end{tabular}

$\mathrm{BED}$, Biological equivalent dose; RT, radiotherapy. ${ }^{*} \alpha / \beta$ ratio of $2.5 \mathrm{~Gy}$ for melanoma.

was no significance different in the 5-year ofRFS between the 2 groups (RT 68\% vs. No-RT 59\%, $p=0.174$; Figure 2A). However, in the high-risk group, there was also a benefit of PORT (RT 93\% vs. No-RT 29\%, $p=0.002$; Figure 2B). Through univariate analysis of high-risk group patients, PORT was the sole meaningful factor for axilla-inguinal RFS and ofRFS (Table III).

Radiotherapy dose. Because we used various conventional RT regimens, we analyzed the effect of BED on local control by classifying the patients into $>90 \mathrm{~Gy}_{2.5}(\mathrm{n}=6)$ and $\leq 90 \mathrm{~Gy}_{2.5}(\mathrm{n}=11)$ groups in high-risk patients. There were no significant differences between the 2 groups in axillainguinal RFS (both 100\%) or ofRFS ( $\leq 90 \mathrm{~Gy}_{2.5} 89 \%$ vs. $>90$ Gy2.5 100\%, $p=0.456$ ).

Patterns of failure. Distant recurrence was the main pattern of failure with 5-year DMFS of 35\% in whole patients. PORT had no effect on the 5-year DMFS in all patients (RT $34 \%$ vs. No-RT $35 \%, p=0.489$ ) or in the high-risk group (RT $56 \%$ vs. No-RT $23 \%, p=0.179)$. There was no significant factor for DMFS in univariate analysis, including interferon alpha-2b and chemotherapy (Table III).

Toxicity. Of the 28 patients who received PORT, 4 (14\%) experienced grade 2 acute radiation dermatitis, but there were no grade $\geq 3$ acute toxicities. There were no grade $\geq 2$ late toxicities, but 2 patients demonstrated grade 1 lymphedema. In the No-RT group, 1 patient showed grade 2 lymphedema after $\mathrm{LN}$ dissection.
Table II. Patient characteristics of the high-risk group.

\begin{tabular}{|c|c|c|c|}
\hline & $\begin{array}{l}\text { RT group } \\
(\mathrm{n}=17)\end{array}$ & $\begin{array}{l}\text { No-RT group } \\
\quad(\mathrm{n}=17)\end{array}$ & $p$-Value \\
\hline Gender & & & 1.000 \\
\hline Male & 10 & 10 & \\
\hline Female & 7 & 7 & \\
\hline Age, y & & & 0.956 \\
\hline Median (range) & $55(46-71)$ & $55(43-82)$ & \\
\hline ECOG performance status & & & 0.434 \\
\hline 0 & 12 & 14 & \\
\hline 1 & 5 & 3 & \\
\hline Primary site & & & 0.530 \\
\hline Arm & 3 & 4 & \\
\hline Leg & 10 & 6 & \\
\hline Trunk & 1 & 2 & \\
\hline Unknown & 3 & 5 & \\
\hline DOI of primary site, $\mathrm{mm}$ & & & 0.171 \\
\hline$\leq 1$ & 1 & 0 & \\
\hline $1.01-2$ & 4 & 2 & \\
\hline $2.01-4$ & 3 & 2 & \\
\hline$>4$ & 3 & 5 & \\
\hline Unknown & 6 & 8 & \\
\hline Pathological subtype & & & 0.849 \\
\hline ALM & 5 & 4 & \\
\hline Non-ALM & 1 & 4 & \\
\hline Unknown & 11 & 9 & \\
\hline LN field & & & 0.501 \\
\hline Axilla & 6 & 8 & \\
\hline Inguinal & 11 & 9 & \\
\hline Number of positive LNs & & & 0.523 \\
\hline Median (range) & $3(1-6)$ & $1(1-11)$ & \\
\hline $\mathrm{LN}$ maximum diameter, $\mathrm{cm}$ & & & 0.212 \\
\hline$<3$ & 8 & 5 & \\
\hline$\geq 3$ & 9 & 11 & \\
\hline Unknown & 0 & 1 & \\
\hline Extranodal extension & & & 0.023 \\
\hline None & 9 & 4 & \\
\hline Present & 4 & 2 & \\
\hline Unknown & 4 & 11 & \\
\hline Type of surgery for LN disease & & & 0.154 \\
\hline Dissection & 15 & 17 & \\
\hline Excision & 2 & 0 & \\
\hline Year of diagnosis for LN disease & & & 0.114 \\
\hline $1997-2006$ & 2 & 6 & \\
\hline $2007-2016$ & 15 & 11 & \\
\hline Recurrent LN disease & & & 0.501 \\
\hline Yes & 8 & 6 & \\
\hline No & 9 & 11 & \\
\hline Use of interferon & & & 0.683 \\
\hline Yes & 3 & 4 & \\
\hline No & 14 & 13 & \\
\hline Use of chemotherapy & & & 0.303 \\
\hline Yes & 1 & 3 & \\
\hline No & 16 & 14 & \\
\hline
\end{tabular}


A

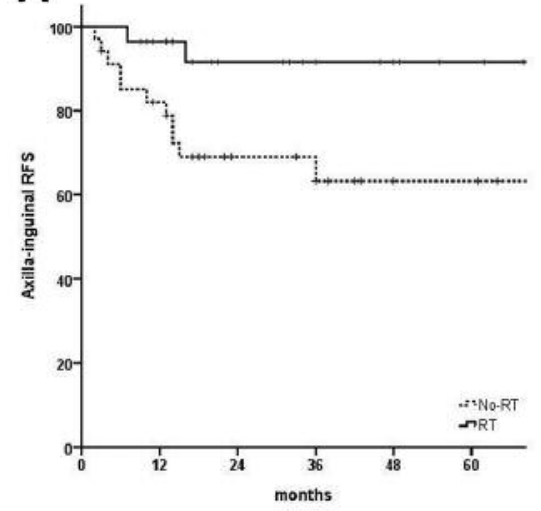

B

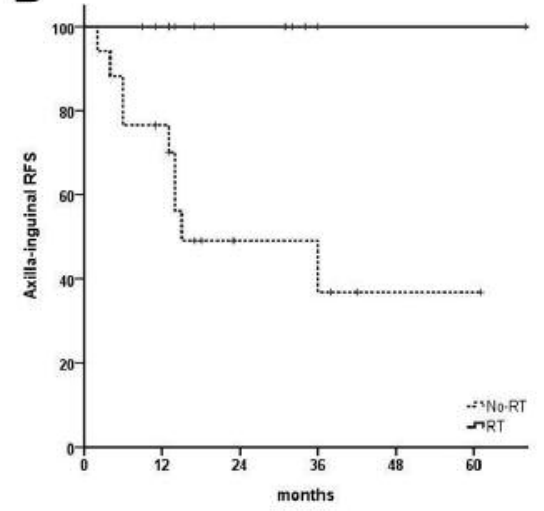

Figure 1. Five-year axilla-inguinal recurrence-free survival outcomes for the entire study cohort, RT 92\% vs. No-RT 63\%, $p=0.019$ (A), and the high-risk group, RT $100 \%$ vs. No-RT 37\%, $p=0.001$ (B).

A

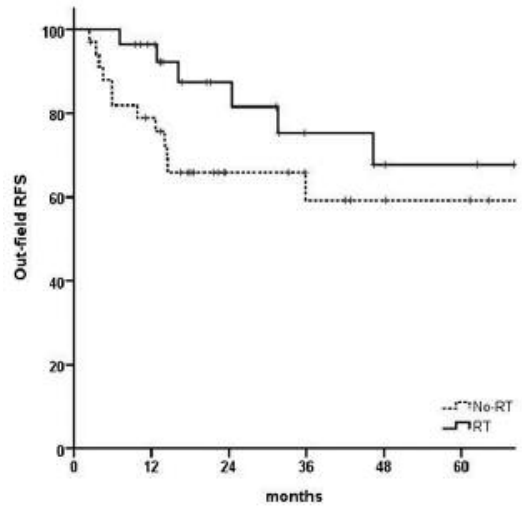

B

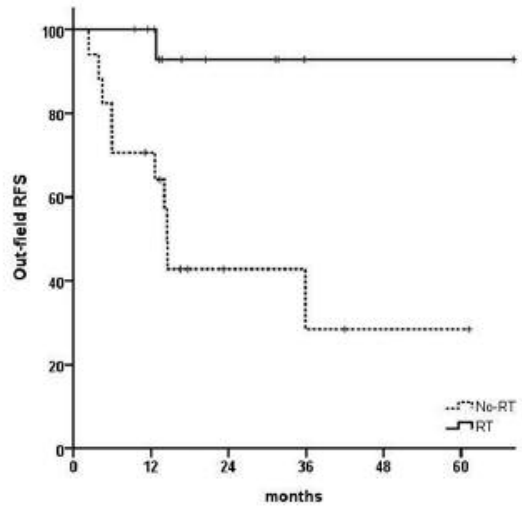

Figure 2. Five-year out-field recurrence-free survival for the entire study cohort, RT 68\% vs. No-RT 59\%, $p=0.174$ (A) and the high-risk group, RT $93 \%$ vs. No-RT $29 \%, p=0.002(B)$.

\section{Discussion}

Current data revealed superior local control of PORT using conventional-fractionation in LN metastasis with high-risk features from cutaneous melanoma. Although these findings had already been shown in a previous randomized phase 3 study $(1,4)$ and several other retrospective studies $(2,3,5$ 8 ), our present study is the first report on an Asian population with different clinicopathological features from Caucasians. Although many different subtypes were missing, about $30 \%$ of patients in the present study had ALM, similar to another Asian series (10).

Furthermore, we reported the result of the PORT using conventional-fractionation with fraction size of 1.8-2.2 Gy. We summarize the previous relevant trials in Table IV. Most of the previous studies used hypofractionated RT, consisting of 30 Gy in 5 fractions, twice a week, and one study utilized
48 Gy in 20 fractions, 5 days per week. Those studies reported 5-year in-field (cervical, axilla, inguinal) RFS rates of $80-90 \%$ in RT groups and rates of $52 \%$ to $72 \%$ in No-RT groups (1-3, 6-8). The results of our present study are comparable to the findings from these former studies (RT $100 \%$ vs. No-RT $37 \%, p=0.001)$.

Despite the evidence supporting a survival benefit of PORT, some clinicians are still reluctant to use it due to the possible long-term morbidity associated with RT. Lymphedema is the most common concern with a large fraction size, particularly for patients receiving PORT in axillary or inguinal regions. For this reason, efforts have been made to compare the established regimen with fraction size of $\geq 6$ Gy to revised regimens using smaller fraction size. The RTOG 83-05 trial randomized patients with measurable melanoma to 32 Gy in 4 fractions weekly vs. 50 Gy in 20 daily fractions (20). Toxicity was greater in $32 \mathrm{~Gy} / 4$ fractions group with each 3 cases of grade 
Table III. Univariate analysis for the 5-year axilla-inguinal RFS, out-field RFS and DMFS in the high-risk group.

\begin{tabular}{|c|c|c|c|c|c|c|c|}
\hline & \multirow[t]{2}{*}{$\mathrm{N}$} & \multicolumn{2}{|c|}{ Axilla-inguinal RFS } & \multicolumn{2}{|c|}{ Out-field RFS } & \multicolumn{2}{|c|}{ DMFS } \\
\hline & & $\%$ & $p$-Value & $\%$ & $p$-Value & $\%$ & $p$-Value \\
\hline Gender & & & 0.625 & & 0.455 & & 0.863 \\
\hline Male & 20 & 64 & & 60 & & 34 & \\
\hline Female & 14 & 66 & & 58 & & 56 & \\
\hline Age, y & & & 0.484 & & 0.524 & & 0.873 \\
\hline$<55$ & 20 & 55 & & 47 & & 44 & \\
\hline$\geq 55$ & 14 & 77 & & 70 & & 40 & \\
\hline ECOG performance status & & & 0.820 & & 0.827 & & 0.238 \\
\hline 0 & 26 & 65 & & 56 & & 48 & \\
\hline 1 & 8 & 66 & & 66 & & 0 & \\
\hline Primary site & & & 0.691 & & 0.979 & & 0.997 \\
\hline Arm & 7 & 69 & & 69 & & 64 & \\
\hline Leg & 16 & 77 & & 63 & & 39 & \\
\hline Trunk & 3 & 0 & & 0 & & 67 & \\
\hline Unknown & 8 & 50 & & 50 & & 36 & \\
\hline Depth of invasion, $\mathrm{mm}$ & & & 0.087 & & 0.296 & & 0.590 \\
\hline$\leq 4$ & 12 & 88 & & 78 & & 50 & \\
\hline$>4$ & 8 & 38 & & 38 & & 60 & \\
\hline Unknown & 14 & 62 & & 55 & & 35 & \\
\hline Pathological subtype & & & 0.877 & & 0.839 & & 0.408 \\
\hline ALM & 9 & 74 & & 61 & & 25 & \\
\hline Non-ALM & 5 & 67 & & 40 & & 0 & \\
\hline Unknown & 20 & 60 & & 60 & & 55 & \\
\hline LN field & & & 0.625 & & 0.864 & & 0.913 \\
\hline Axilla & 14 & 68 & & 68 & & 56 & \\
\hline Inguinal & 20 & 67 & & 56 & & 38 & \\
\hline Number of positive LNs & & & 0.780 & & 0.877 & & 0.712 \\
\hline$<3$ & 17 & 56 & & 51 & & 50 & \\
\hline$\geq 3$ & 17 & 71 & & 64 & & 32 & \\
\hline $\mathrm{LN}$ maximum diameter, $\mathrm{cm}$ & & & 0.692 & & 0.748 & & 0.666 \\
\hline$<3$ & 13 & 60 & & 60 & & 58 & \\
\hline$\geq 3$ & 20 & 63 & & 51 & & 37 & \\
\hline Unknown & 1 & - & & - & & 0 & \\
\hline Extranodal extension & & & 0.474 & & 0.444 & & 0.794 \\
\hline None & 13 & 81 & & 72 & & 46 & \\
\hline Present & 6 & 83 & & 83 & & 67 & \\
\hline Unknown & 15 & 52 & & 44 & & 32 & \\
\hline Type of surgery for LN disease & & & 0.478 & & 0.407 & & 0.448 \\
\hline Dissection & 32 & 63 & & 56 & & 42 & \\
\hline Excision & 2 & - & & - & & 50 & \\
\hline Year of diagnosis for LN disease & & & 0.362 & & 0.919 & & 0.332 \\
\hline 1997-2006 & 8 & 88 & & 50 & & 34 & \\
\hline 2007-2016 & 26 & 68 & & 60 & & 28 & \\
\hline Recurrent LN disease & & & 0.652 & & 0.827 & & 0.315 \\
\hline Yes & 14 & 66 & & 66 & & 43 & \\
\hline No & 20 & 66 & & 55 & & 40 & \\
\hline Use of $\mathrm{RT}^{\mathrm{a}}$ & & & 0.001 & & 0.002 & & 0.179 \\
\hline Yes & 17 & 100 & & 93 & & 56 & \\
\hline No & 17 & 37 & & 29 & & 23 & \\
\hline Use of interferon & & & 0.495 & & 0.859 & & 0.273 \\
\hline Yes & 7 & 57 & & 57 & & 57 & \\
\hline No & 27 & 68 & & 59 & & 37 & \\
\hline Use of chemotherapy & & & 0.256 & & 0.479 & & 0.144 \\
\hline Yes & 4 & 38 & & 38 & & 25 & \\
\hline No & 30 & 68 & & 60 & & 44 & \\
\hline
\end{tabular}

ALM, Acral lentiginous melanoma; LN, lymph node; RFS, recurrence-free survival; RT, radiotherapy. aSignificant factor in univariate analysis $(p<0.05)$. 
Table IV. Summary of previous reports on the treatment results of cutaneous melanoma with LN metastasis.

\begin{tabular}{|c|c|c|c|c|c|c|c|c|}
\hline Study & Design & $\begin{array}{l}\text { Number of } \\
\text { patients }\end{array}$ & $\begin{array}{l}\mathrm{LN} \\
\text { field }\end{array}$ & $\begin{array}{c}\text { High risk } \\
\text { definition } \\
\text { (RT indication) }\end{array}$ & $\begin{array}{l}\text { RT dose } \\
(\mathrm{Gy}) / \\
\text { fractions }\end{array}$ & $\begin{array}{c}\text { Median } \\
\text { f/u } \\
\text { (months) }\end{array}$ & $\begin{array}{l}\text { 5-year in-field } \\
\text { (cervical, axilla, } \\
\text { inguinal) RFS }\end{array}$ & Toxicity \\
\hline $\begin{array}{l}\text { Burmeister } \\
{[1]} \\
(2012)\end{array}$ & Prospective & $\begin{array}{c}\text { RT (123) } \\
\text { No-RT (127) }\end{array}$ & $\begin{array}{l}\text { Cervical, Axilla, } \\
\text { Inguinal }\end{array}$ & $\begin{array}{c}\text { Axilla ( } \geq 2 \mathrm{LNs}), \\
\text { Inguinal ( } \geq 3 \mathrm{LNs} \text {, } \\
\text { ENE, Size } \geq 4 \mathrm{~cm}\end{array}$ & $48 / 20$, daily & 40 & $\begin{array}{c}\begin{array}{c}\text { Cumulative local } \\
\text { relapse in eligible } \\
\text { population }\end{array} \\
\text { RT 20/109 }(18 \%) v s . \\
\text { No-RT } 34 / 108(31 \%) \\
\text { HR: } 0.56(p=0.041)\end{array}$ & $\begin{array}{c}\text { Acute } \geq \text { grade } \\
3 \text { toxicity } \\
\text { RT } 15 \% \\
\text { No report on } \\
\text { late toxicity }\end{array}$ \\
\hline $\begin{array}{l}\text { Agrawal } \\
{[2]} \\
(2014)\end{array}$ & Retrospective & $\begin{array}{c}\text { RT (509), } \\
\text { No-RT (106) }\end{array}$ & $\begin{array}{l}\text { Cervical, Axilla, } \\
\text { Inguinal }\end{array}$ & $\begin{array}{c}\geq 4 \text { LNs, ENE, } \\
\quad \text { Size } \geq 3 \mathrm{~cm}\end{array}$ & $\begin{array}{c}\text { 30/5, twice } \\
\text { weekly }\end{array}$ & 60 & $\begin{array}{c}\text { RT } 87 \% \text { vs. } 52 \% \\
\quad(p<0.0001)\end{array}$ & $\begin{array}{c}5 \text {-year } \geq \text { grade } \\
2 \text { toxicity } \\
\text { RT } 20 \% \text { vs. } \\
\text { No-RT } 13 \%, \\
p=0.004\end{array}$ \\
\hline $\begin{array}{l}\text { Bibault } \\
{[3]} \\
(2011)\end{array}$ & Retrospective & $\begin{array}{c}\text { RT (60), } \\
\text { No-RT (26) }\end{array}$ & $\begin{array}{l}\text { Cervical, Axilla, } \\
\text { Inguinal }\end{array}$ & $\begin{array}{c}\geq 4 \text { LNs, ENE, } \\
\text { Size } \geq 3 \mathrm{~cm}\end{array}$ & $\begin{array}{c}\text { 30/5, twice } \\
\text { weekly }\end{array}$ & 73 & $\begin{array}{c}\text { Axilla: RT (dose } \\
>50 \text { Gy) } 90 \% \text { vs. } \\
\text { No-RT } 70 \% \\
\text { Inguinal: } 80 \% \\
\text { vs. } 72 \% \\
(p=0.004)\end{array}$ & $\begin{array}{c}\text { Late grade } 2 \\
\text { toxicity } \\
\text { RT } 22 \% \text { vs. } \\
\text { No-RT } 27.3 \% \\
\text { No } \geq \text { grade } 3 \\
\text { toxicity }\end{array}$ \\
\hline $\begin{array}{l}\text { Ballo } \\
{[4]} \\
(2006)\end{array}$ & Retrospective & RT (466) & $\begin{array}{l}\text { Cervical, Axilla, } \\
\text { Inguinal }\end{array}$ & $\begin{array}{l}\geq 4 \text { LNs, ENE, } \\
\text { Size } \geq 3 \mathrm{~cm}, \\
\text { Recurrent LN }\end{array}$ & $\begin{array}{c}\text { 30/5, twice } \\
\text { weekly }\end{array}$ & 50.3 & $89 \%$ & $\begin{array}{c}\text { 5-year } \geq \text { grade } \\
2 \text { toxicity } \\
\text { RT } 19 \%\end{array}$ \\
\hline $\begin{array}{l}\text { Chang } \\
{[5]} \\
(2006)\end{array}$ & Retrospective & RT (56) & $\begin{array}{c}\text { Cervical, Axilla, } \\
\text { Inguinal }\end{array}$ & $\begin{array}{l}\geq 3 \text { LNs, ENE, } \\
\text { Size } \geq 3 \mathrm{~cm}, \\
\text { Recurrent LN }\end{array}$ & $\begin{array}{l}\text { 30/5, twice } \\
\text { weekly } \\
60 / 30, \text { daily }\end{array}$ & 20.4 & $87 \%$ & $\begin{array}{c}\text { Acute grade } \\
2 \text { toxicity: } 2 \% \\
\text { Serious late in } \\
\text { hypo- } \\
\text { fractionation } \\
\text { group: } 5 \%\end{array}$ \\
\hline Current & Retrospective & $\begin{array}{l}\text { High risk } \\
\text { RT (17), } \\
\text { No-RT (17) }\end{array}$ & Axilla, Inguinal & $\begin{array}{c}\geq 3 \mathrm{LN}, \mathrm{ENE} \\
\text { Size } \geq 3 \mathrm{~cm}\end{array}$ & Mainly 50/25 & 22 & $\begin{array}{l}\text { RT } 100 \% \text { vs. } \\
\text { No-RT } 37 \% \\
(p=0.001)\end{array}$ & $\begin{array}{l}\text { Acute grade } \\
2 \text { toxicity: } \\
18 \%(14 \% \\
\text { in total RT } \\
\text { group) } \\
\text { No late } \\
\text { toxicity } \geq \\
\text { grade2 }\end{array}$ \\
\hline
\end{tabular}

ENE, Extranodal extension; HR, hazard ratio; LN, lymph node; RFS, recurrence-free survival; RT, radiotherapy.

3 and 4 toxicities. However, only grade 3 toxicities in 4 patients were noted in $50 \mathrm{~Gy} / 20$ fractions arm. No difference in the response rates was found between the 2 arms.

In the postoperative setting, Chang et al. (7) retrospectively compared hypofractionated and conventional RT. Significant late complications occurred in 2 patients who received hypofractionation $(5 \%)$. The result compares favorably with other studies using hypofractionation in Table IV, which demonstrated $\geq$ grade 2 late toxicity rate of $\sim 20 \%$. Since $87 \%$ of patients in Chang et al. had melanoma in head and neck region known to present low incidence of lymphedema unlike axilla and groin (6). With the patients who irradiated to axillary and inguinal area, the present study reported the acceptable toxicity rate of acute grade 2 radiation dermatitis of $14 \%$ and no grade $\geq 2$ late toxicity including lymphedema. Also, our results showed comparable tumor control with the previous studies. (Table IV) We thus suggest that conventionalfractionation would be adequate for local control with low toxicity rates in patients with high-risk factors for regional relapse. Moreover, with advances in the planning and delivery of external beam RT such as intensity-modulated RT (IMRT) and volumetric-modulated RT (VMAT), we expect further decreases in toxicity. Indeed, Mattes et al. (21) performed dosimetric comparison of axilla and inguinal RT techniques and reported the advantages of IMRT and VMAT over the 3DCRT used in our present study.

PORT had no effect on DMFS, and the other systemic therapies also failed to demonstrate benefit in univariate 
analysis. Because distant metastasis is the major pattern of failure, effort is required to update systemic therapeutic approaches. Biochemotherapy, which includes cisplatin, vinblastine, dacarbazine, interleukin-2, and interferon, has shown a better median RFS of 4 years compared with 1.9 years for high-dose interferon alpha-2b alone in completely resected stage III melanoma patients $(p=0.03)$ (22). In addition, high-dose ipilimumab, a monoclonal antibody directed at the immune checkpoint receptor CTLA-4, improved the RFS of fully resected stage III melanoma in the EORTC 18071 trial (5-year RFS 40.8\% with ipilimumab vs. $30.3 \%$ with placebo, $p<0.001)(23)$.

The current study was limited by its retrospective nature; missing pathologic reports may have affected the results, and toxicities might have been underestimated. Radiotherapy dose regimens were also heterogenous. Due to the rarity of cutaneous melanoma in South Korea, the sample size was small. In addition, we collected patients over quite an extended period and there could have been an undetectable bias due to developments in surgery, RT techniques, and imaging quality. Despite the limitations, our present data reproduced the conclusion of a previous randomized phase 3 study (1), guaranteeing the reliability of our analysis.

In accordance with our findings in an Asian population, we defined high-risk patients as those with $\geq 3 \mathrm{LNs}$, size $\geq 3 \mathrm{~cm}$, extranodal extension. PORT showed a significant improvement in local control with minimal toxicity for Asian cutaneous melanoma patients with $\mathrm{LN}$ metastasis. In addition, we suggest that PORT using conventional fractionation with 50 Gy in 2 Gy per fraction could be another option of PORT for LN metastasis from cutaneous melanoma with the above high-risk factors.

\section{Conflicts of Interest}

None declared.

\section{Acknowledgements}

This research was supported by Basic Science Research Program through the National Research Foundation of Korea (NRF) funded by the Ministry of Education (NRF-2013R1A1A2011346) and by a grant of the Korea Health Technology R\&D Project through the Korea Health Industry Development Institute (KHIDI), funded by the Ministry of Health \& Welfare, Republic of Korea (grant number: HI 15C0972).

\section{References}

1 Burmeister BH, Henderson MA, Ainslie J, Fisher R, Di Iulio J, Smithers BM, Hong A, Shannon K, Scolyer RA and Carruthers $\mathrm{S}$ : Adjuvant radiotherapy versus observation alone for patients at risk of lymph-node field relapse after therapeutic lymphadenectomy for melanoma: a randomised trial. Lancet Oncol 13: 589-597, 2012.
2 Agrawal S, Kane JM, 3rd, Guadagnolo BA, Kraybill WG and Ballo MT: The benefits of adjuvant radiation therapy after therapeutic lymphadenectomy for clinically advanced, high-risk, lymph node-metastatic melanoma. Cancer 115: 5836-5844, 2009.

3 Bibault J-E, Dewas S, Mirabel X, Mortier L, Penel N, Vanseymortier L and Lartigau E: Adjuvant radiation therapy in metastatic lymph nodes from melanoma. Radiat Oncol 6: 12, 2011.

4 Henderson MA, Burmeister BH, Ainslie J, Fisher R, Di Iulio J, Smithers BM, Hong A, Shannon K, Scolyer RA, Carruthers S, Coventry BJ, Babington S, Duprat J, Hoekstra HJ and Thompson JF: Adjuvant lymph-node field radiotherapy versus observation only in patients with melanoma at high risk of further lymphnode field relapse after lymphadenectomy (ANZMTG 01.02/TROG 02.01): 6-year follow-up of a phase 3, randomised controlled trial. Lancet Oncol 16: 1049-1060, 2015.

5 Keenan LG, O'Sullivan S, Glynn A, Higgins M, Flavin A and Brennan S: Clinical review of treatment outcomes and patterns of failure with adjuvant radiotherapy in node-positive malignant melanoma. J Med Imaging Radiat Oncol 61: 258-262, 2017.

6 Ballo MT, Ross MI, Cormier JN, Myers JN, Lee JE, Gershenwald JE, Hwu P and Zagars GK: Combined-modality therapy for patients with regional nodal metastases from melanoma. Int J Radiat Oncol Biol Phys 64: 106-113, 2006.

7 Chang DT, Amdur RJ, Morris CG and Mendenhall WM: Adjuvant radiotherapy for cutaneous melanoma: comparing hypofractionation to conventional fractionation. Int $\mathrm{J}$ Radiat Oncol Biol Phys 66: 1051-1055, 2006.

8 Lee RJ, Gibbs JF, Proulx GM, Kollmorgen DR, Jia C and Kraybill WG: Nodal basin recurrence following lymph node dissection for melanoma: implications for adjuvant radiotherapy. Int J Radiat Oncol Biol Phys 46: 467-474, 2000.

9 Geller AC, Swetter SM, Brooks K, Demierre MF and Yaroch AL: Screening, early detection, and trends for melanoma: current status (2000-2006) and future directions. J Am Acad Dermatol 57: 555-572, 2007.

10 Lee HY, Chay WY, Tang M, Chio M and Tan SH: Melanoma: differences between Asian and Caucasian patients. Ann Acad Med Singapore 41: 17-20, 2012.

11 Jung HJ, Kweon SS, Lee JB, Lee SC and Yun SJ: A clinicopathologic analysis of 177 acral melanomas in Koreans: relevance of spreading pattern and physical stress. JAMA Dermatol 149: 1281-1288, 2013.

12 Cormier JN, Xing Y, Ding M, Lee JE, Mansfield PF, Gershenwald JE, Ross MI and Du XL: Ethnic differences among patients with cutaneous melanoma. Arch Intern Med 166: 19071914, 2006.

13 Sasaki Y, Niu C, Makino R, Kudo C, Sun C, Watanabe H, Matsunaga J, Takahashi K, Tagami H, Aiba $\mathrm{S}$ and Horii A: BRAF point mutations in primary melanoma show different prevalences by subtype. J Invest Dermatol 123: 177-183, 2004.

14 Si L, Kong Y, Xu X, Flaherty KT, Sheng X, Cui C, Chi Z, Li S, Mao L and Guo J: Prevalence of BRAF V600E mutation in Chinese melanoma patients: large scale analysis of BRAF and NRAS mutations in a 432-case cohort. Eur J Cancer 48: 94-100, 2012.

15 Jin SA, Chun SM, Choi YD, Kweon SS, Jung ST, Shim HJ and Yun SJ: BRAF mutations and KIT aberrations and their clinicopathological correlation in 202 Korean melanomas. J Invest Dermatol 133: 579-582, 2013. 
16 Dossgg LL and Memula N: The radioresponsiveness of melanoma. Int J Radiat Oncol Biol Phys 8: 1131-1134, 1982.

17 Fertil B and Malaise E: Intrinsic radiosensitivity of human cell lines is correlated with radioresponsiveness of human tumors: analysis of 101 published survival curves. Int J Radiat Oncol Biol Phys 11: 1699-1707, 1985.

18 Shashanka R and Smitha B: Head and neck melanoma. ISRN Surg 2012: 948302, 2012.

19 Overgaard J: The role of radiotherapy in recurrent and metastatic malignant melanoma: a clinical radiobiological study. Int $\mathbf{J}$ Radiat Oncol Biol Phys 12: 867-872, 1986.

20 Sause W, Cooper J, Rush S, Ago C, Cosmatos D, Coughlin C, Janjan $\mathrm{N}$ and Lipsett $\mathrm{J}$ : Fraction size in external beam radiation therapy in the treatment of melanoma. Int J Radiat Oncol Biol Phys 20: 429-432, 1991.

21 Mattes MD, Zhou Y, Berry SL and Barker CA: Dosimetric comparison of axilla and groin radiotherapy techniques for highrisk and locally advanced skin cancer. Radiati Oncol J 34: 145, 2016.
22 Flaherty LE, Othus M, Atkins MB, Tuthill RJ, Thompson JA, Vetto JT, Haluska FG, Pappo AS, Sosman JA and Redman BG: Southwest Oncology Group S0008: A phase III trial of high-dose interferon alfa- $2 \mathrm{~b}$ versus cisplatin, vinblastine, and dacarbazine, plus interleukin-2 and interferon in patients with high-risk melanoma - An intergroup study of cancer and leukemia Group B, Children's Oncology Group, Eastern Cooperative Oncology Group, and Southwest Oncology Group. J Clin Oncol 32: 37713778, 2014.

23 Eggermont AM, Chiarion-Sileni V, Grob J-J, Dummer R, Wolchok JD, Schmidt H, Hamid O, Robert C, Ascierto PA and Richards JM: Prolonged survival in stage III melanoma with ipilimumab adjuvant therapy. New Engl J Med 375: 1845-1855, 2016.

Received May 24, 2017

Revised June 25, 2017

Accepted June 26, 2017 